\title{
Defining the Critical Region for Intellectual Disability and Brain Malformations in 6q27 Microdeletions
}

\author{
Marcela D. Hanna ${ }^{a, b}$ Patricia N. Moretti ${ }^{c}$ Claudiner P. de Oliveira ${ }^{d}$ \\ Maria T.A. Rosa ${ }^{d}$ Beatriz R. Versiani ${ }^{e}$ Silviene F. de Oliveira ${ }^{a}$ b Aline Pic- \\ Taylor $^{\mathrm{a}, \mathrm{b}}$ Juliana F. Mazzeu ${ }^{\mathrm{a}, \mathrm{c}}$ \\ a Programa de Pós-Graduação em Ciências da Saúde, Faculdade de Ciências da Saúde, Universidade de Brasília, \\ Brasília, Brazil; ${ }^{b}$ Departamento de Genética e Morfologia, Instituto de Ciências Biológicas, Universidade de Brasília, \\ Brasília, Brazil; ' ${ }^{C}$ aculdade de Medicina, Universidade de Brasília, Brasília, Brazil; ${ }^{d}$ Secretaria de Estado de Saúde do \\ Distrito Federal, Brasília, Brazil; ${ }^{e}$ Hospital Universitário de Brasília, Universidade de Brasília, Brasília, Brazil
}

\section{Keywords}

Brain malformation - Chromosome microarray analysis .

Intellectual disability $\cdot 6 q 27$ microdeletion

\begin{abstract}
Terminal microdeletions of the long arm of chromosome 6 are associated with a phenotype that includes multiple brain malformations, intellectual disability, and epilepsy. A 1.7-Mb region has been proposed to contain a gene responsible for the brain anomalies. Here, we present the case of a 12-yearold girl with multiple brain alterations and moderate intellectual disability with a 18-kb deletion in chromosome 6q27, which is smaller than the microdeletions previously described by microarray analysis. We refined the smallest region of overlap possibly associated with the phenotype of brain malformations and intellectual disability to a segment of $325 \mathrm{~kb}$, comprising the DLL1, PSMB1, TBP, and PDCD2 genes since these genes were structurally and/or functionally lost in the smaller deletions described to date. We hypothesize that $D L L 1$ is responsible for brain malformations and possibly interacts with other adjacent genes. The TBP gene encodes a transcription factor which is potentially re-
\end{abstract}

\section{KARGER}

(c) 2019 S. Karger AG, Basel

E-Mail karger@karger.com

www.karger.com/msy lated to cognitive development. TBP is linked to PSMB1 and $P D C D 2$ in a conserved manner among mammals, suggesting a potential interaction between these genes. In conclusion, the 6 q27 microdeletion is a complex syndrome with variable expressivity of brain malformations and intellectual disability phenotypes which are possibly triggered by the 4 genes described and adjacent genes susceptible to gene regulation changes.

(c) 2019 S. Karger AG, Basel

Identifying the causes of brain malformations (BM) and intellectual disability (ID) is a common challenge in clinical practice. Among the genetic causes of these multifactorial signs is the presence of terminal deletions in chromosome 6q, denoting that genes in this region might play a key role in normal brain development in humans [Eash et al., 2005; Bertini et al., 2006]. Terminal deletions in chromosome $6 \mathrm{q}$ are associated with a variable pheno-

M.D.H. and P.N.M. share first authorship.
Aline Pic-Taylor or Juliana F. Mazzeu

Instituto de Ciências Biológicas and Faculdade de Medicina, Universidade de Brasília Asa Norte

Brasília, DF 70910-900 (Brazil)

E-Mail alinepic@unb.br or julianamazzeu@unb.br 
type including ID, seizures, facial dysmorphisms, heart defects, ear and eye abnormalities, and different BM, such as agenesis of the corpus callosum, periventricular nodular heterotopia (PNH), polymicrogyria, hydrocephalus, and cerebellar malformations [Peddibhotla et al., 2015]. However, the severity of the phenotype does not correlate with the size of the rearrangements, thus suggesting a minimal critical region with a major contribution to the phenotype. In this context, Peddibhotla et al. [2015] proposed a small region of overlap (SRO) of $1.7 \mathrm{Mb}$ containing dose-sensitive genes responsible for BM in patients with a 6q deletion based on chromosome microarray analysis (CMA), whereby haploinsufficiency of one or more of these genes would interfere with embryogenesis and lead to abnormal development of the nervous system [Peddibhotla et al., 2015].

Refining the extent of the deletion in $6 \mathrm{q}$ to a minimum number of genes could help to understand how each gene effects ID manifestation and brain abnormalities. Aiming to establish phenotype-genotype correlation, in this study, we present the case of a patient and her mother, carriers of the smallest $6 \mathrm{q} 27$ deletion registered using CMA to date, who present ID isolated or associated with BM.

\section{Patients and Methods}

Patient 1 was a 12-year-old girl born to unrelated parents. She was born at term, weighed 3,100 g (50-75th percentile) and measured $51 \mathrm{~cm}$ (75-90th percentile). Both parents were 22 years old at the time of birth. She walked at 14 months, but preferred toe walking.

At the age of 3, a CCT scan revealed hydrocephalus, incomplete hippocampal inversion, reduced mesencephalic volume, and reduced peritrigonal white matter. At the age of 6 , a brain MRI showed subependymal heterotopia, hypoplastic vermis, an enlargement of the supratentorial ventricular system, and symmetric hippocampi with preserved shape.

On clinical examination at the age of 11 , the patient weighed $32.1 \mathrm{~kg}$ (10-25th percentile), height was $141 \mathrm{~cm}$ (25-50th percentile), and her head circumference was $51.8 \mathrm{~cm}$ (25th percentile). She presented with a low temporal hairline, frontal hypertrichosis, epicanthal folds, a broad nasal bridge with a bulbous tip, a short philtrum, prominent lips, a high palate, protruding ears with overfolded helices, slender fingers, and irregular creases on her left hand. Panoramic radiography showed hypodontia, with agenesis of 2 premolars (15 and 35). She has moderate ID and is unable to read, write, or understand numbers. According to her mother, she can speak, but during the appointment she only uttered some noises and pointed to objects. She has never experienced a seizure. Toe walking remained evident, and she had pseudo-hypertrophic leg muscles, possibly due to abnormal gait.

Patient 2, the girl's mother, was 33 years old and presented with brachycephaly, a high forehead, a bulbous nose tip, medium phil- trum, thin lips, retrognathia, and slender fingers. Her brain MRI was normal, but she had moderate ID. The woman stated that she is able to read and write, but has difficulty comprehending texts and is unable to read more challenging words.

CMA was performed using a CytoScan 750K (Affymetrix) and analyzed with Chromosome Analysis Suite (ChAS) 2.0 software (Affymetrix). Since the CytoScan $750 \mathrm{~K}$ platform can test nonpolymorphic and polymorphic probes simultaneously, correlating the CNVs detected with patient's allelic information, we did not perform other validation methods.

\section{Results}

The clinical and neuroimaging characteristics of our patients are presented in Table 1 and compared with the other 12 cases described in the literature. The most common phenotypes observed in the subset of patients analyzed were developmental delay and/or learning difficulties observed in $86 \%$ of the patients $(12 / 14)$ and structural brain anomalies also detected in $86 \%(12 / 14)$ of the patients.

G-banding did not reveal any chromosome abnormalities, and both patients had a 46,XX karyotype.

CMA identified a $325-\mathrm{kb}$ deletion in chromosome 6: arr[hg19] 6q27(170,589,000-170,914,297) $\times 1$ extending to the telomere (518 kb in total) (Fig. 1). This region comprises 6 genes: DLL1, FAM120B, MIR4644, PSMB1, TBP, and PDCD2. On further investigation, CMA of the mother revealed that the deletion was inherited. Other benign CNVs located at $6 \mathrm{p} 21.33$ were detected in patient 1, but were not related with the patient's phenotype. Patient 2 presented other benign CNVs at 8q21.13 and 5q33.2 described in the literature as polymorphic.

\section{Discussion and Conclusion}

The $6 \mathrm{q} 27$ microdeletion presents variable expressivity, and there is no clear correlation between deletion size and phenotype severity [Bertini et al., 2006]. The most common BM observed in patients with this microdeletion are corpus callosum abnormalities, $\mathrm{PNH}$, hydrocephalus, polymicrogyria, and cerebellar malformations [Peddibhotla et al., 2015]. There is no characteristic facial gestalt associated with the microdeletion. Structural brain abnormalities and developmental delay have been described both in patients with smaller and larger deletions [Peddibhotla et al., 2015]. Furthermore, severe phenotypes such as alobar holoprosencephaly (HPE) have been described in patients with deletions ranging from 2.2 to $12.3 \mathrm{Mb}$ [Dupe et al., 2011]. Here, 


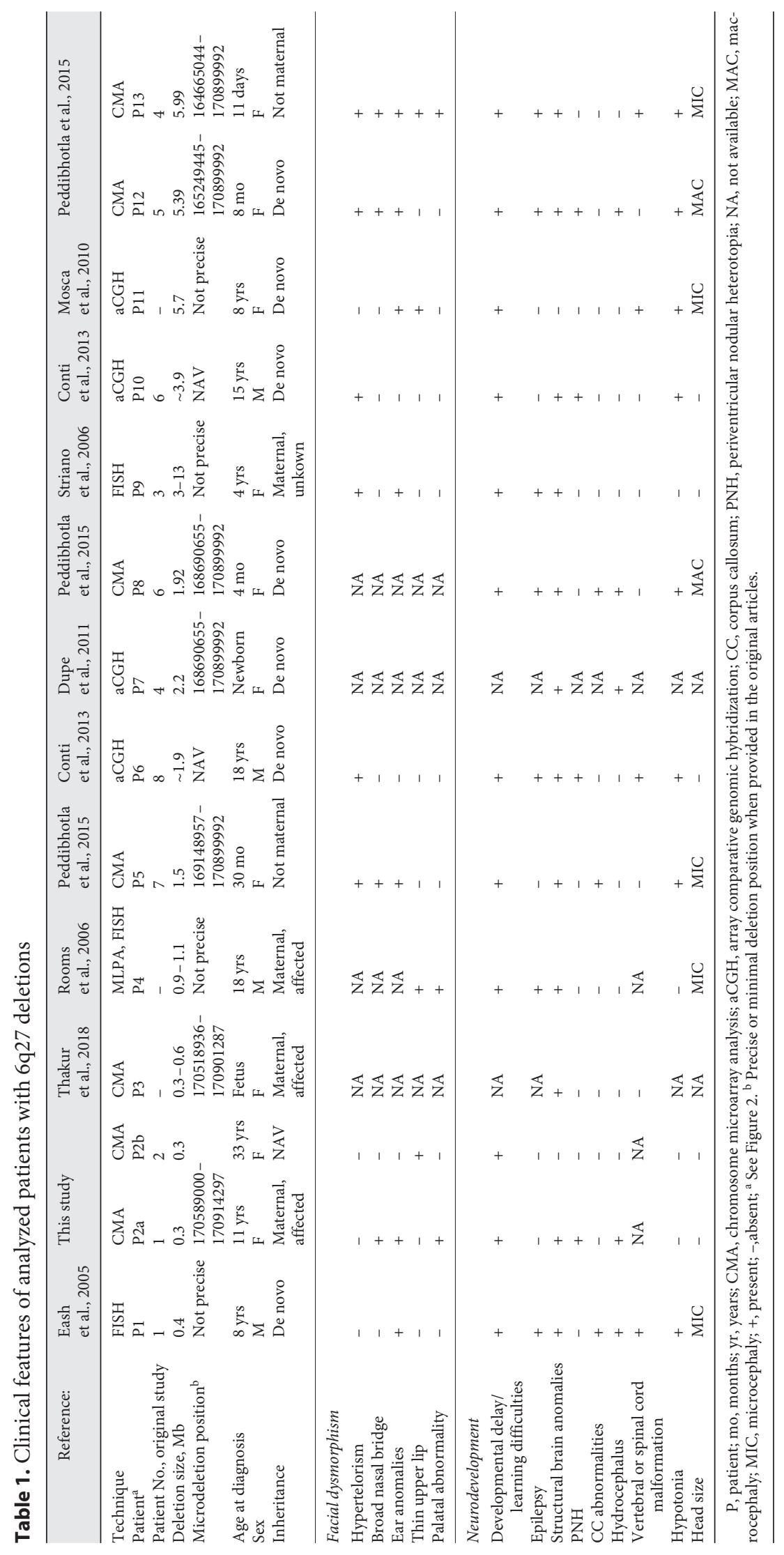




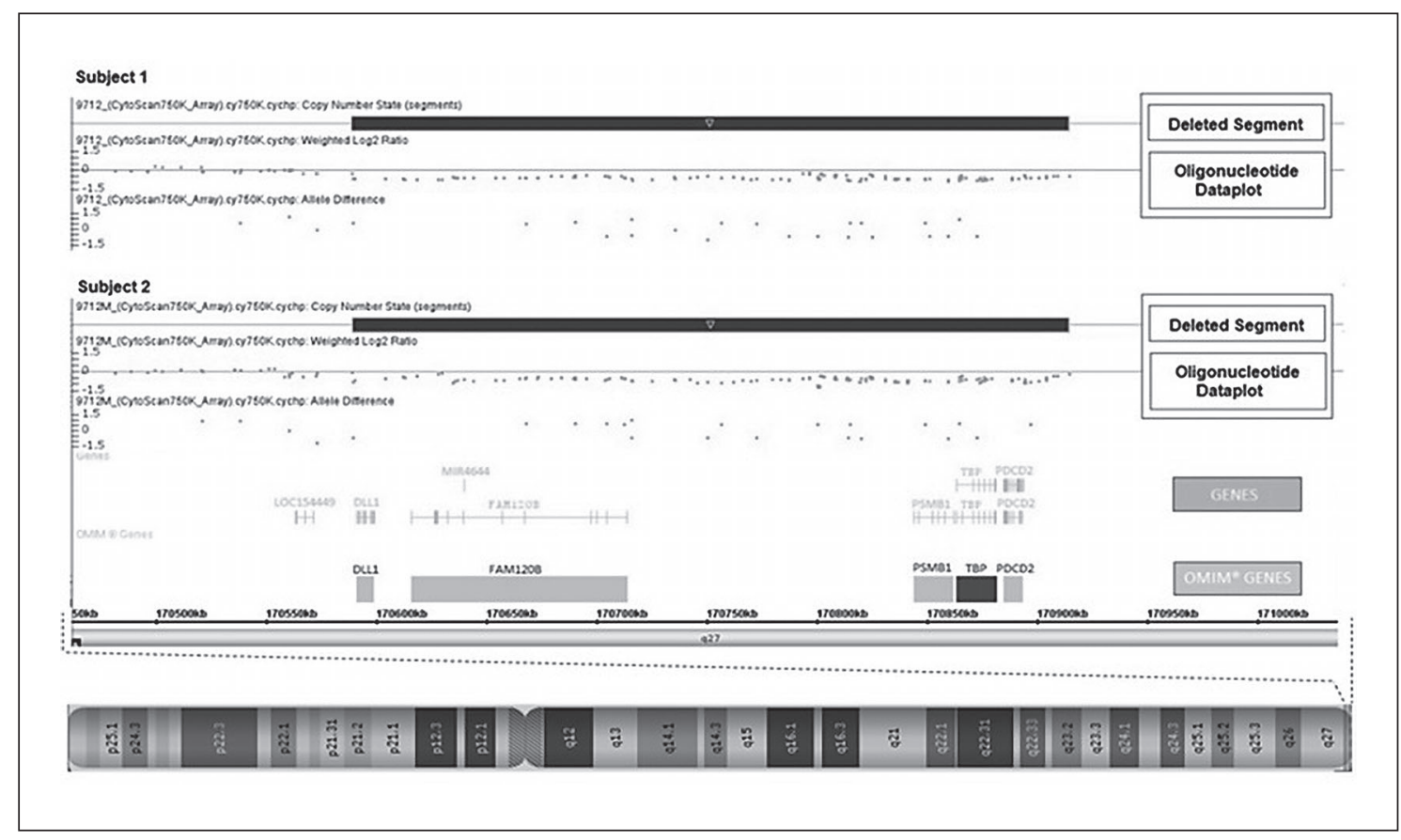

Fig. 1. Analysis of the $6 \mathrm{q} 27$ region encompassing the microdeletion described in our study. Chromosome microarray analysis oligonucleotide data plot depicting the microdeletion observed in patients 1 and 2. Known genes and genes described in the OMIM dataset mapped in the region of the microdeletion are presented below.

we report a patient with ID, BM, and mild dysmorphic features with a small terminal $6 \mathrm{q} 27$ microdeletion inherited from her mother who also presents ID, but not BM. This microdeletion distally overlaps the smallest deletion described to date using FISH [Eash et al., 2005] and proximally to other major microdeletions described in $6 \mathrm{q} 27$ [Conti et al., 2013], comprising the PSMB1, TBP, PDCD2, DLL1, FAM120B, and MIR4644 genes (Fig. 2).

Attempts to define a critical region for brain abnormalities have been made, but different genes are involved depending on the patients analyzed. Peddibhotla et al. [2015] defined the $\mathrm{SRO}$ as a $1.7-\mathrm{Mb}$ telomeric region carrying the THBS2, WDR27, PHF10, TCTE3, ERMARD, LOC154449, $D L L 1, F A M 120 B, P S M B 1, T B P$, and $P D C D 2$ genes. In a previous study, a 1.2-Mb SRO was defined in the interstitial segment that includesTHBS2, WDR27, PHF10, TCTE3, ERMARD, LOC154449, and DLL1 [Conti et al., 2013].

The smallest deletion described in the $6 \mathrm{q} 27$ region associated with ID and BM was detected by FISH and has approximately $400 \mathrm{~kb}$. This deletion includes a 200-kb segment of subtelomeric DNA, consisting of 3 coding genes: PSMB1, TBP, and PDCD2 extending to the telomere [Eash et al., 2005]. This deletion is located distal to the SRO proposed by Conti et al. [2013]. A similar small deletion was recently described by Thakur et al. [2018] involving 7 genes (DLL1, FAM120B, PSMB1, TBP, PDCD2, LOC154449, and MIR4644) detected by CGH, a technique capable of precisely detecting breakpoints.

Comparing the different $6 \mathrm{q}$ microdeletion cases described in the literature (Table 1), we refined the SRO possibly associated with the phenotype of BM and ID to a region containing $D L L 1, P S M B 1, T B P$, and $P D C D 2$ since these genes that have actually been structurally and/ or functionally lost in the smaller deletions described to date. In the $6 \mathrm{q} 27$ region, the abovementioned genes appear to act in complementary ways, and possibly the deletion of one of these central genes could be sufficient to induce phenotype abnormalities.

DLL1 is a Notch ligand and contributes to neural precursor cell differentiation into neurons in mice [Kawaguchi et al., 2008]. Haploinsufficiency of DLL1 in humans has been implicated in HPE [Dupe et al., 2011]. According to a study that compared the expression of DLL1 and ERMARD in $\mathrm{PNH}$, silencing of ERMARD was the main cause of the abnormality, with DLL1 contributing at a smaller level [Conti et al., 2013]. In our patient, ERMARD was not deleted, yet PNH was observed, possibly due to DLL1 impairment. These findings suggest that more than 
Fig. 2. Size, extent, and genomic content of the $6 \mathrm{q} 27$ deletions. Deleted regions are shown (gray bars). The dark gray bar represents our patients. Dashed lines indicate the minimal region of overlap detected between patients. P14-P21 harbor deletions $>6 \mathrm{Mb}$ and represent the patients described in the following studies: Peddibhotla et al., 2015 (patients 2, 3); Bertini et al., 2006 (patients 1, 2); Striano et al., 2006 (patients 2, 4, 5), and Eash et al., 2005 (patient 2).

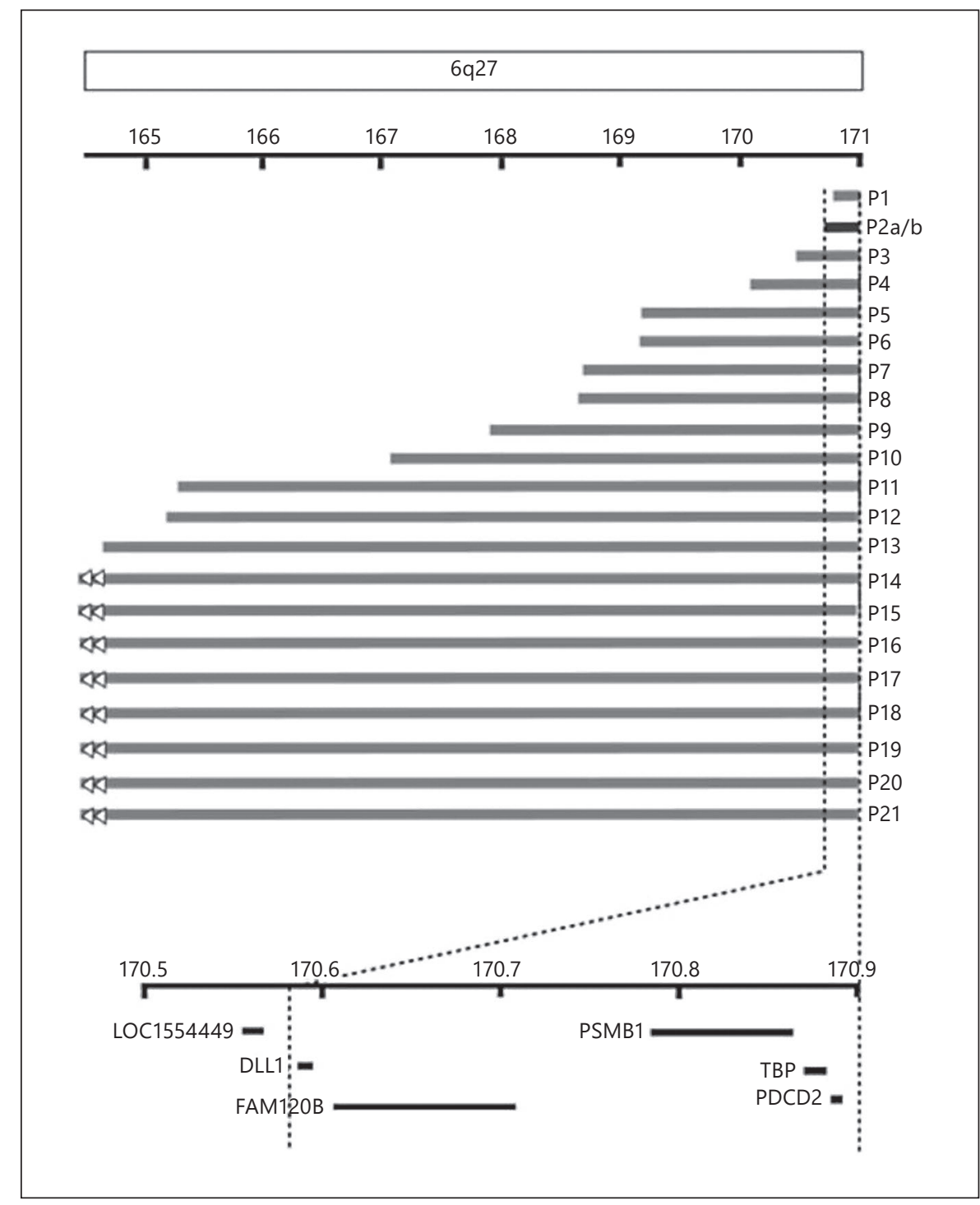

one gene in the $6 \mathrm{q}$ terminal region may contribute to different BM, with ERMARD and DLL1 responsible for $\mathrm{PNH}$. Although DLL1 was not deleted in the patient described by Eash et al. [2005], it is possible that DLL1 expression could be altered due to a position effect or by the disruption of topologically associated domains (TADs). The influence of microdeletions on gene expression of adjacent sequences, due to position effect as well as distant sequences by TADs disruption, have been described in the literature [Merla et al., 2006; Lupiañez et al., 2016]. This patient does not present with $\mathrm{PNH}$, whereas our patient does. Our hypothesis is that DLL1 is the main cause of PNH. The phenotypic differences between these patients could be explained by the deletion of DLL1 in con- junction with the lower expression of adjacent genes caused by position effect.

The TBP gene encodes a TATA-binding protein, an essential transcription factor for initiating transcription. $T B P$ is highly expressed in brain tissues and has been identified as a candidate gene for ID [Rooms et al., 2006]. Monozygotic twins with a subtelomeric $6 \mathrm{q}$ deletion, encompassing the PDCD2, PSMB1, TBP, and DLL1 genes, showed generalized epilepsy, larger cisterna magna, and colpocephaly [Rooms et al., 2006].

The PDCD2 gene is associated with programmed cell death in thymocytes. Both PDCD2 and PSMB1 are tightly linked to $T B P$. These genes are nonrandomly distributed in both mammalian and invertebrate genomes and 
are possibly associated with ID and BM phenotype due to their TBP interaction [Rooms et al., 2006].

The PSMB1 gene encodes a subunit of a proteasome complex [Rooms et al., 2006] and is involved in a variety of other processes, such as cell cycle regulation, antigen presentation, and inflammatory response [Goldberg et al., 1995]. Besides its linkage to $P D C D 2$ and TBP, we hypothesize that the $P S M B 1$ gene could interfere with DLL1 function by ATP-dependent degradation of ubiquitinated proteins. Ubiquitination is possibly important for Notch activation, given that a 3-bp deletion in the DLL1 gene affecting 2 amino acids in a conserved region with the ubiquitin motif was reported in a patient with semilobar HPE [Dupe et al., 2011].

Two other genes deleted in our patients were $F A M 120 B$ and MIR4644. However, a possible role of these genes in causing BM and ID is unclear, and although this is the case, we cannot exclude a possible effect of losing noncoding sequences, and consequently changing regulatory cascades, in these phenotypes.

In 6q27 deletion carriers, the phenotypes vary from patients presenting with both ID and BM [Eash et al., 2005; Bertini et al., 2006; Rooms et al., 2006; Striano et al., 2006; Dupe et al., 2011; Peddibhotla et al., 2015; also see DECIPHER patient 346644] to mild ID without dysmorphic features/structural brain anomalies [Mosca et al., 2010; also see DECIPHER patient 2188], similar to what we observed in our patient's mother. Besides variable expressivity, another explanation for the lack of structural $\mathrm{BM}$ in the mother is incomplete penetrance, considered by other authors [Le Caignec et al., 2005; Dupe et al., 2011], although the mechanisms remain unclear to date. Furthermore, the lack of hotspots for chromosome breakage [Eash et al., 2005; Striano et al., 2006] that allow chromosomal deletions of various sizes and contents could also account for the phenotypic range in patients with the $6 \mathrm{q} 27$ deletion. In addition, other studies observed that patients who inherited the deletion had more severe phenotypes [Goldberg et al., 1995; Le Caignec et al., 2005; Conti et al., 2013], thus suggesting a possible generation effect. This could be explained by the presence of second hits, either in association with low-frequency SNPs of the remained deleted CNV or other CNVs in the proband genome [Watson et al., 2014]. Moreover, we cannot exclude the fact that penetrance/expressivity of genetic mutations can be modulated by environmental interactions, and these are not easy to address.

In conclusion, 6q27 microdeletion is a complex syndrome with variable expressivity and incomplete penetrance. Deletion size has no correlation to phenotype se- verity, and no hotspots were identified. Here, we described the detection of a microdeletion that overlaps the smaller region previously described in 6q27 and propose refinement of the SRO to a fragment containing only the 4 genes that were mainly responsible for the BM and DI encountered in the patients with the 6p27 microdeletion.

\section{Acknowledgments}

We thank the patient and her family for participating in the study. We are also grateful to Dr. Valerio Conti for patient information and software illustration as well as Michael Taylor for English revision of the manuscript.

\section{Statement of Ethics}

The study was approved by the University of Brasilia ethical committee (2.261.862/2017), which conforms to the standards specified in the Helsinki declaration. Informed consent was obtained for molecular studies and image use.

\section{Disclosure Statement}

The authors declare no conflicts of interest involving this research.

\section{Funding Sources}

This work was supported by FAPDF (0193.000.936/2015), Ministério da Saúde (PPSUS 2010/193.000.344/2010), and CAPES.

\section{Author Contributions}

M.D. Hanna, P.N. Moretti, J. Forte Mazzeu, and A. Pic-Taylor analyzed the data, searched the literature, and wrote the first draft of the manuscript. J. Forte Mazzeu, S.F. de Oliveira, and A. PicTaylor were the coordinators of the study and responsible for grant support. C.P. de Oliveira performed the experiments. M.T. Alves Rosa and B. Ribeiro Versiani performed the clinical evaluation of the patients. All the authors revised the manuscript providing important intellectual content. 


\section{References}

Bertini V, De Vito G, Costa R, Simi P, Valetto A: Isolated $6 \mathrm{q}$ terminal deletions: an emerging new syndrome. Am J Med Genet A 140:74-81 (2006).

-Conti V, Carabalona A, Pallesi-Pocachard E, Parrini E, Leventer RJ, et al: Periventricular heterotopia in $6 \mathrm{q}$ terminal deletion syndrome: role of the C6orf70 gene. Brain 136:33783394 (2013).

Dupe V, Rochard L, Mercier S, Le Petillon Y, Gicquel I, et al: NOTCH, a new signaling pathway implicated in holoprosencephaly. Hum Mol Genet 20:1122-1131 (2011).

-Eash D, Waggoner D, Chung J, Stevenson D, Martin CL: Calibration of $6 \mathrm{q}$ subtelomere deletions to define genotype/phenotype correlations. Clin Genet 67:396-403 (2005).

-Goldberg AL, Stein R, Adams J: New insights into proteasome function: from archaebacteria to drug development. Chem Biol 2:503-508 (1995).

Kawaguchi D, Yoshimatsu T, Hozumi K, Gotoh Y: Selection of differentiating cells by different levels of delta-like 1 among neural precursor cells in the developing mouse telencephalon. Development 135:3849-3858 (2008).
Le Caignec C, Boceno M, Saugier-Veber P, Jacquemont $\mathrm{S}$, Joubert $\mathrm{M}$, et al: Detection of genomic imbalances by array based comparative genomic hybridisation in fetuses with multiple malformations. J Med Genet 42: 121-128 (2005).

Lupiañez DG, Spielmann M, Mundlos S: Breaking TADs: how alterations of chromatin domains result in disease. Trends Genet 32:225237 (2016).

Merla G, Howald C, Henrichsen CN, Lyle R, Wyss C, et al: Submicroscopic deletion in patients with Williams-Beuren syndrome influences expression levels of the nonhemizygous flanking genes. Am J Hum Genet 79:332-341 (2006).

Mosca AL, Callier P, Masurel-Paulet A, ThauvinRobinet C, Marle N, et al: Cytogenetic and array-CGH characterization of a 6 q27 deletion in a patient with developmental delay and features of Ehlers-Danlos syndrome. Am J Med Genet A 152A:1314-1317 (2010).
Peddibhotla S, Nagamani SC, Erez A, Hunter JV, Holder JL Jr, et al:Delineation of candidate genes responsible for structural brain abnormalities in patients with terminal deletions of chromosome 6q27. Eur J Hum Genet 23:5460 (2015).

Rooms L, Reyniers E, Scheers S, van Luijk R, Wauters J, et al: TBP as a candidate gene for mental retardation in patients with subtelomeric $6 \mathrm{q}$ deletions. Eur J Hum Genet 14: 1090-1096 (2006).

Striano P, Malacarne M, Cavani S, Pierluigi M, Rinaldi $\mathrm{R}$, et al: Clinical phenotype and molecular characterization of $6 \mathrm{q}$ terminal deletion syndrome: five new cases. Am J Med Genet A 140:1944-1949 (2006).

Thakur M, Bronshtein E, Hankerd M, Adekola H, Puder K, et al: Genomic detection of a familial $382 \mathrm{~Kb} 6 \mathrm{q} 27$ deletion in a fetus with isolated severe ventriculomegaly and her affected mother. Am J Med Genet A 176:1985-1990 (2018).

Watson CT, Marques-Bonet T, Sharp AJ, Mefford $\mathrm{HC}$ : The genetics of microdeletion and microduplication syndromes: an update. Annu Rev Genomics Hum Genet 15:215-244 (2014). 